\title{
Pharmacy Technicians' Perception About Symptoms and Concerns of Older Patients Visiting Pharmacies: A Cross-Sectional Study
}

This article was published in the following Dove Press journal: Journal of Multidisciplinary Healthcare

\author{
Katharina Homann (iD) ${ }^{1,2}$ \\ Thilo Bertsche (iD) ${ }^{1,2}$ \\ Susanne Schiek (iD) 1,2 \\ 'Department of Clinical Pharmacy, \\ Institute of Pharmacy, Faculty of \\ Medicine, Leipzig University, Leipzig, \\ Germany; ${ }^{2}$ Drug Safety Center, \\ University Hospital Leipzig, Leipzig \\ University, Leipzig, Germany
}

\begin{abstract}
Purpose: Older patients are still not sufficiently integrated into multidisciplinary care concepts including geriatric and palliative care. They do, however, regularly visit pharmacies to fill prescriptions or to buy self-medication. Thus, they have frequent contact with pharmacy technicians (PTs), who are widely involved in counselling in Germany. However, it is not known whether geriatric symptoms are recognized by PTs and to what extent older patients use their pharmacy to address geriatric or palliative concerns. This study aimed to investigate PTs' impression of older patients' symptoms, geriatric and palliative concerns in consultations, as well as multidisciplinary collaboration.
\end{abstract}

Patients and Methods: We conducted a cross-sectional study in April-May 2019. Using a self-administered questionnaire, PTs were asked about (i) geriatric symptoms, (ii) geriatric and palliative concerns older patients expressed in routine consultations, (iii) supposed reasons for inadequate care, and (iv) PTs' desire for multidisciplinary cooperation.

Results: (i) The 5 most common symptoms the 339 participating PTs recognized in the community pharmacy were pain, insomnia, restricted mobility, eye disorders, and constipation. (ii) The three most frequently addressed non-drug-related geriatric palliative concerns were mental strain, loneliness, and mourning. (iii) As reasons for inadequate patient care, PTs predominantly mentioned patient-related reasons (299 of 518 reasons, $58 \%$ ). (iv) $85 \%$ of the PTs desired closer cooperation with general practitioners, $84 \%$ with nursing services and $39 \%$ with palliative physicians.

Conclusion: PTs frequently saw older patients visiting the pharmacy who suffer from a variety of symptoms. PTs were additionally confronted with diverse geriatric or palliative concerns. We deduce, first, a need for PT training in geriatric and palliative care. Second, multidisciplinary care concepts and research should include pharmacies because they seem to be a low-threshold contact to older patients, who might need access to adequate care.

Keywords: geriatrics, palliative care, interdisciplinary health team, community pharmacy, symptom burden

\section{Introduction}

Older patients frequently have multimorbidity. They often suffer from lifethreatening diseases and multiple symptoms that have a negative impact on their quality of life. ${ }^{1-4}$ They further frequently have to deal with the death of companions and their own oncoming end of life and increasing frailty. ${ }^{5,6}$ Additionally, they can be overwhelmed with managing their life and therapy. Geriatric medicine and
Department of Clinical Pharmacy, Institute of Pharmacy, Faculty of Medicine Leipzig University, Brüderstr. 32, Leipzig 04103 , Germany

Tel +4934 I 97 I I 800

Fax +493419711849

Email thilo.bertsche@uni-leipizig.de
Journal of Multidisciplinary Healthcare 2021:14 103-II4 
palliative care address these issues. Both are multidisciplinary overlapping concepts focusing on the quality of life. ${ }^{7,8}$ They are both holistic approaches that include physical, mental, social and spiritual dimensions of the patients' health care issues. Initiatives also claim to implement geriatric palliative care as an "interspecialty collaboration" between the two fields. ${ }^{9}$ However, older patients are still not sufficiently integrated into those multidisciplinary health structures. ${ }^{10}$ Consequently, strategies have been implemented to close this gap and to identify patients with severe chronic diseases, who would benefit from palliative care. However, although training for this early identification is still limited mostly to general practitioners, ${ }^{11}$ it is worth looking at other contact points with older patients where they can be transfered to geriatric and palliative care structures.

Older patients and their relatives regularly visit their pharmacies to collect prescriptions or to buy selfmedication to treat minor ailments. ${ }^{12,13}$ With increasing age, patients visit their pharmacy even more frequently than they visit their general practitioner. ${ }^{14}$ Therefore, pharmacies represent a low-threshold contact point for patients and their relatives. Current pharmaceutical care services contribute to optimizing older patients' therapy by assisting in administration problems, performing medication reviews or monitoring possible adverse reactions. ${ }^{15,16}$ Geriatric and especially palliative aspects are considered only to a low extent in current pharmacy services. It is unknown to what extent the pharmaceutical staff recognizes patients' symptoms during pharmacy consultations. Knowledge about this would allow an estimate of how many patients visiting pharmacies suffer from symptoms and might be inadequately treated. However, no data exist on whether older patients currently address general health issues including geriatric and palliative concerns in their pharmacy consultations. If they do, pharmacies could serve to fill some of the missing connections between older people and geriatric and palliative care resources.

In Germany, pharmacies must be owned and operated by a pharmacist. The supportive pharmaceutical staff includes employed pharmacists and pharmacy technicians (PTs). PTs represent the largest proportion of pharmaceutical staff. To become a PT, they need to pass a two-year program at a specialized PT school and a half year of practical training in a pharmacy. Because of their nonacademic qualifications, they work under the attendance and supervision of pharmacists. Within this framework, PTs advise on and dispense prescribed drugs and self- medication and are frequently the patient's first point of contact in community pharmacies. Especially in the context of counselling in self-medication, the PTs need to clarify the patient's symptoms to evaluate the limits of self-medication and to recommend an appropriate product. Few studies have addressed the role of PTs in patient counselling, so far. To assure a more realistic and wider view of older patients relating to their everyday enquiries in pharmacies; however, PTs can be an important source.

This study, therefore, aimed to investigate the PTs' impression of older patients' symptoms, geriatric and palliative concerns in pharmacy consultations, as well as the multidisciplinary collaboration.

\section{Patients and Methods \\ Study Design}

A cross-sectional study was performed by using an anonymous self-administered questionnaire.

\section{Development of the Questionnaire}

An expert panel consisting of three pharmacists with experience in palliative and geriatric pharmacy and research developed the questionnaire, based on the validated Memorial Symptom Assessment Scale (MSAS), an unvalidated questionnaire by Somers et al 2003, and the unvalidated Common Terminology Criteria for Adverse Events (CTCAE), Version 5.0 from the National Cancer Institute. ${ }^{17-19}$

The final questionnaire consists of four parts (Supplements 1 and 2):

(i) Question 1a-c: Geriatric symptoms should include typical geriatric and palliative symptoms as well as common adverse drug events. We defined 20 symptoms based on MSAS, Sommers et al and used the terminology of the CTCAE. ${ }^{17-19}$ The questions of the MSAS, which addresses the patients themselves, were modified to represent the perspective of PTs. After a pretest, a question about the need for support was added. Frequency was measured via a 5-point Likert scale (none/a few/many/ most/all), impairment via a 4-point Likert scale (severe/ moderate/mild/no), and the need for support via a 5-point Likert scale (never/rarely/occasionally/often/always).

(ii) Question 2a-b: Geriatric palliative concerns should cover common geriatric, palliative and pharmaceutical issues that are attributed to older patients. For this purpose, the expert panel defined 9 drug-related and 10 non-drugrelated geriatric palliative concerns of older patients, based 
on literature. ${ }^{20-22}$ To determine the frequency and the need for support, we used the same questions and scales as in part (i).

(iii) Question 3: We additionally asked open questions about the PTs opinions of the reasons for inadequate care.

(iv) Question 4-6: Desire for multidisciplinary cooperation and counselling of older patients: We asked the participants to rank five current activities in the community pharmacy according to their frequency and importance. Closed questions rated the existing cooperation with other professional groups and the desire for more multidisciplinary collaboration. Questions in part (iii) and (iv) were not based on former questionnaires.

Demographic data (Question 7-14, sex, age, profession, professional experience, hours worked per week, hours spent in counselling, size of the pharmacy) were reported at the end of the survey.

The questionnaire was pretested cognitively by nine pharmacists as well as three PTs (target group). Based on the pretest, the phrasing of questions and written instructions for answering the questions were modified to ensure comprehensibility and adapt the vocabulary to the PTs' level of understanding. Based on feedback from the respondents, the rating scale (question $1 \mathrm{a}, 1 \mathrm{c}, 2 \mathrm{a}$, 2b) was extended by adding the middle category "many"/"occasionally" to a 5-point Likert scale. One question was deleted, because its content was beyond the PTs' responsibility, and one open question was deleted because it turned out to be too complex to be answered precisely by the PTs. In part (i), a question about the need for support was added. Questions in part (iv) were modified to reach a better understanding.

None of the pharmacists and PTs involved in the pretest were involved in the development of the study protocol or the main survey. The results of the pretests were not included in the final data analysis.

\section{Participants and Data Collection}

We performed this cross-sectional study between April and May 2019 during a voluntary advanced training session for PTs organized by the Lower Saxony Chamber of Pharmacists. We chose this setting to obtain direct access to PTs, who are difficult to reach by other communication channels.

The total training took part in 12 different settings in Lower Saxony and consisted of 6 different, self-standing one-hour lectures: 'high blood pressure - killer on silent soles', 'nutritional supplements with vitamins D and
Table I Characteristics of Respondents

\begin{tabular}{|c|c|c|}
\hline Characteristics $(\mathrm{N}=339)$ & \multicolumn{2}{|c|}{ Value } \\
\hline \multicolumn{3}{|l|}{ Gender } \\
\hline Male [N (\%)] & 3 & $(1 \%)$ \\
\hline Female $[\mathrm{N}(\%)]$ & 333 & $(98 \%)$ \\
\hline Divers [N (\%)] & 1 & $(<1 \%)$ \\
\hline No response $[\mathrm{N}(\%)]$ & 2 & $(1 \%)$ \\
\hline Age in years [Median (Q25/Q75; Min-Max)] & 43 & $\begin{array}{l}(33 / 53 \\
18-63)\end{array}$ \\
\hline $\begin{array}{l}\text { Professional experience in years [Median } \\
\text { (Q25/Q75; Min-Max)] }\end{array}$ & 20 & $\begin{array}{l}(10 / 30 \\
0.75-45)\end{array}$ \\
\hline $\begin{array}{l}\text { Working time in hours per week [Median } \\
\text { (Q25/Q75, Min-Max)] }\end{array}$ & 30 & $\begin{array}{l}(22.75 / 38 \\
3.5-40)\end{array}$ \\
\hline $\begin{array}{l}\text { Working time [\%] for counselling older } \\
\text { patients [Median (Q25/Q75; Min-Max)] }\end{array}$ & 50 & $\begin{array}{l}(30 / 65 \\
5-100)\end{array}$ \\
\hline \multicolumn{3}{|l|}{ Circumference of the pharmacy } \\
\hline $\begin{array}{l}\text { Big city (number of inhabitants }>100,000)[N \\
(\%)]\end{array}$ & 45 & $(13 \%)$ \\
\hline $\begin{array}{l}\text { Medium-sized city (number of inhabitants } \\
20,000-100,000)[N(\%)]\end{array}$ & 84 & $(25 \%)$ \\
\hline $\begin{array}{l}\text { Small town (number of inhabitants } \\
5000-20,000)[N(\%)]\end{array}$ & 131 & $(39 \%)$ \\
\hline $\begin{array}{l}\text { Rural community (number of inhabitants < } \\
5000)[N(\%)]\end{array}$ & 66 & $(20 \%)$ \\
\hline No response $[\mathrm{N}(\%)]$ & 13 & $(4 \%)$ \\
\hline \multicolumn{3}{|l|}{ Pharmacy is connected to ${ }^{a} \ldots$} \\
\hline Nursing home/assisted living [N (\%)] & 250 & $(74 \%)$ \\
\hline None $[N(\%)]$ & 61 & $(18 \%)$ \\
\hline Palliative network [N (\%)] & 68 & $(20 \%)$ \\
\hline Senior network [N (\%)] & 30 & $(9 \%)$ \\
\hline Nursing Service/Home care ${ }^{b}[N(\%)]$ & 29 & $(9 \%)$ \\
\hline Hospice $[N(\%)]$ & 18 & $(5 \%)$ \\
\hline Social ambulance ${ }^{\mathrm{b}}[\mathrm{N}(\%)]$ & 3 & $(1 \%)$ \\
\hline Oncological practice [N (\%)] & 2 & $(1 \%)$ \\
\hline
\end{tabular}

Notes: ${ }^{\mathrm{a} M u l t i p l e ~ s e l e c t i o n ~ p o s s i b l e ; ~}{ }^{\mathrm{b}}$ Self-mentioned aspects.

B12', 'self-medication during pregnancy', 'sleeping disorders', 'reasons and therapy for dizziness', and 'home remedy kits for older patients'. The participants received the questionnaire at the end of the lecture about home remedy kits for older patients. None of the topics on the questionnaire were addressed by the lectures.

The inclusion criterion was that the respondents work as PTs in community pharmacies. At least 50\% of questions in the questionnaire had to be answered to be included in the data analysis.

The questionnaires were either collected on site by the last lecturer of the day, or sent via fax by the participants themselves. 
How many of your older patients suffer from the following symptoms?

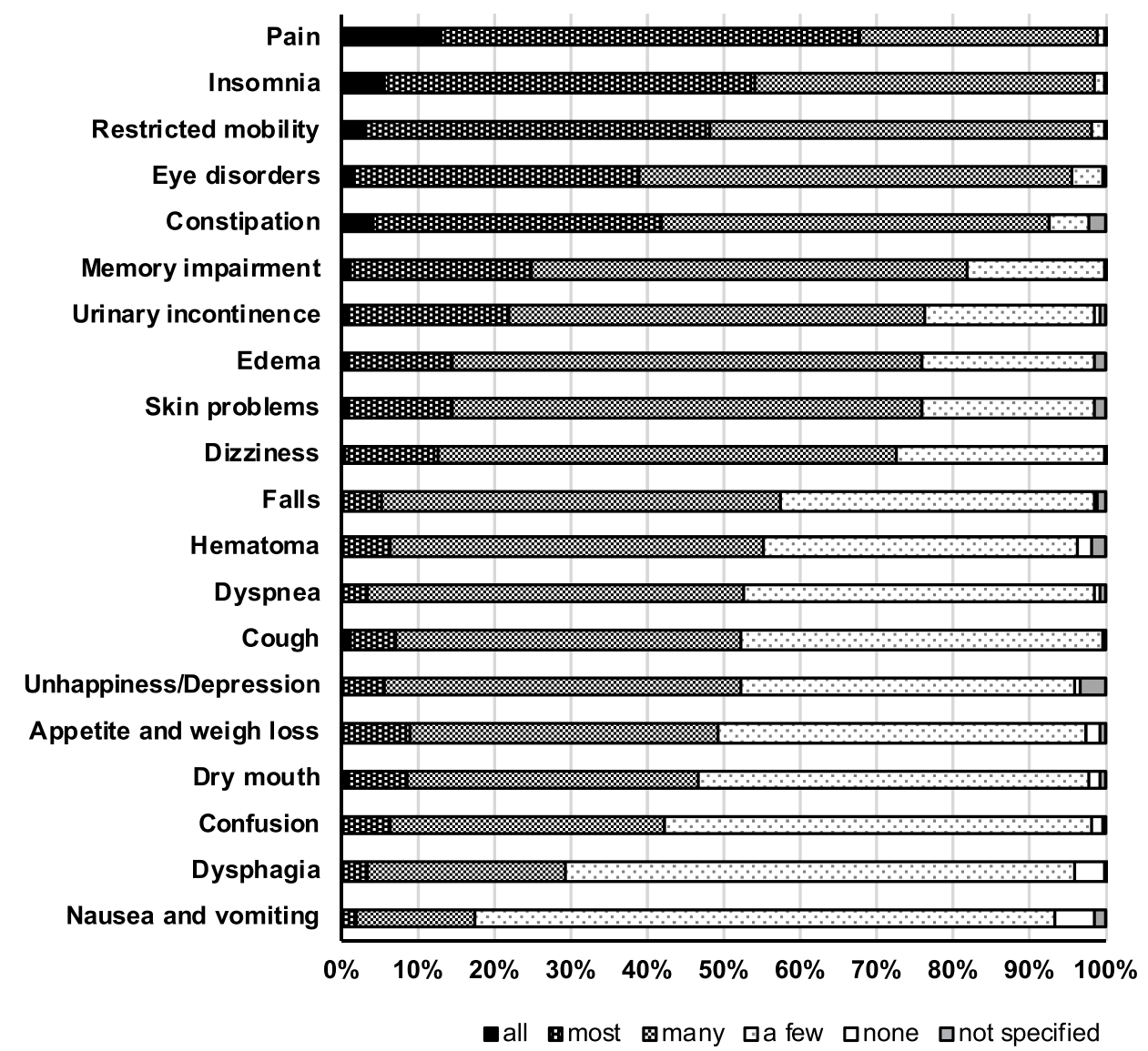

Figure I PTs' impression of symptom prevalence in older patients in pharmacy consultations. Percentages refer to the total number of $\mathrm{N}=339$ respondents.

\section{Data Analysis}

The completed paper-based questionnaires were electronically scanned and converted using FormPro3 (OCR system, Leipzig, Germany). Quantitative data analysis was conducted with Microsoft Excel 2016 (Microsoft Corporation, Redmond, Washington, USA). The nominal and ordinal data were computed with absolute numbers $(\mathrm{N})$ and relative $(\%)$ frequencies. Missing data were described as "not specified". Answers in parts (i) and (ii) were analyzed in Likert scales. The individual reports to open questions of part (iii) were classified post hoc independently by two pharmacists and frequency of each reason for inadequate care was analyzed. In part (iv), the respondents' individual rankings about the importance and extent of every item (1-5) were summarized. The items were then sorted in ascending order based on their sums to build a summative rank of all respondents (1 to 5).

\section{Ethics}

This study was conducted using an anonymous selfadministered questionnaire. Participants who worked in the health sector were asked about their professional experience. According to the German regulations of ethical standards, ethical approval is necessary only if epidemiological research includes personally identifiable information. This was not the case in this study. The Chamber of Pharmacists of Lower Saxony was informed about the study in advance and gave its consent. Consent to participate in the study was given by voluntarily completing the questionnaire. When returning the questionnaire by fax, it was pointed out that data protection would be respected on the spot. Additionally, faxes were to be returned with the number suppressed. 
In your opinion, how much do the following symptoms affect the respective older patients in general?

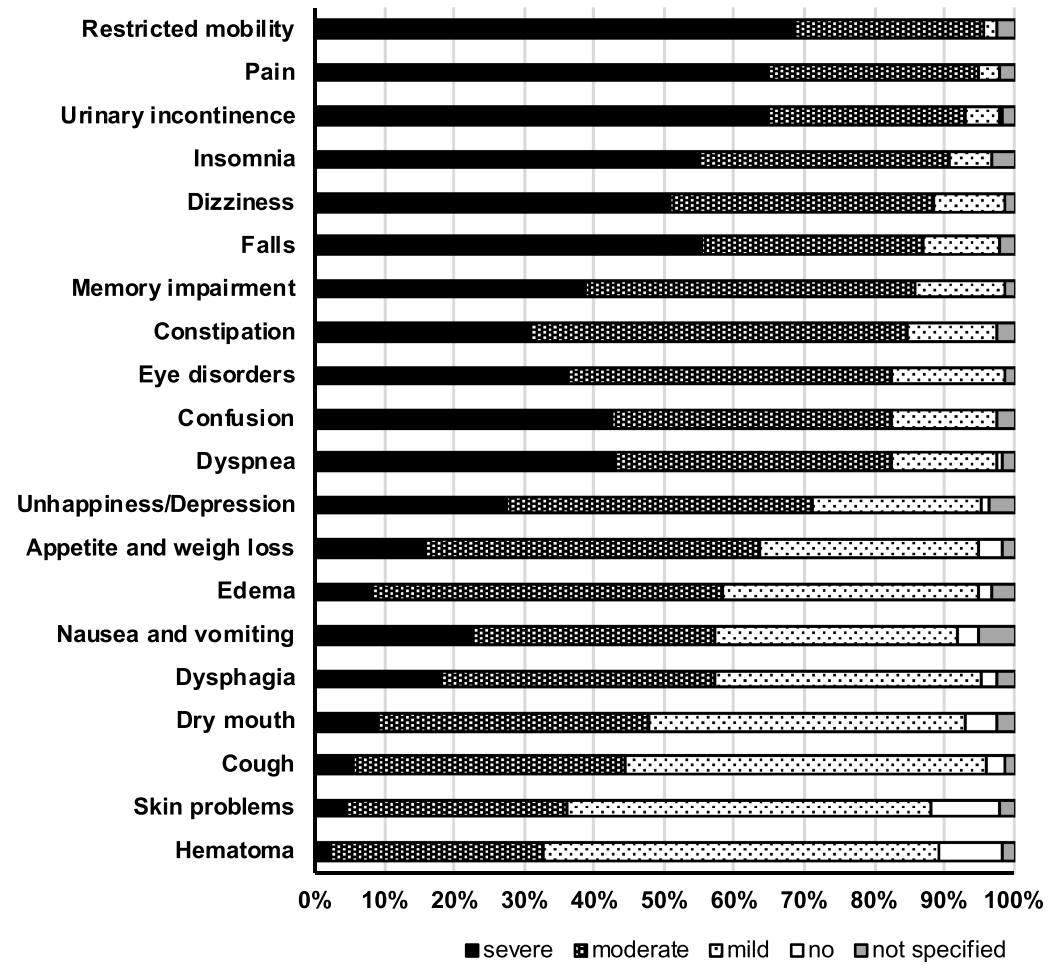

Figure 2 PTs' impression of whether symptoms impair older patients in pharmacy consultations. Percentages refer to the total number of $\mathrm{N}=339$ respondents.

\section{Results}

\section{Respondent Characteristics}

In total, all 831 training participants were invited to answer the questionnaire; 361 of them (43\%) responded: 340 questionnaires were collected during the training, and 21 were sent by fax after the training. Twenty-two respondents did not fulfill the inclusion criteria (9 questionnaires were filled out by pharmacists and in 13, the respondents filled out less than $50 \%$ of the questionnaire).

Three hundred and thirty-nine questionnaires were, therefore, included in the data analysis. Three hundred and thirty-three $(98 \%)$ of the participants were female, three (1\%) male. The median age (Min-Max) of the participating attendees was 43 (18-63) years old; they had a professional experience of $20(0.75-45)$ years in community pharmacy and counselled older patients during $50 \%$ of their working time (5-100\%, Table 1).

\section{Survey Part (I): Geriatric Symptoms}

The five most common geriatric symptoms the PTs recognized in the community pharmacy were pain, insomnia, restricted mobility, eye disorders and constipation (Figure 1). Twelve of the 20 suggested symptoms were recognized as generally "severe" by more than one quarter of the respondents (Figure 2). For 13 of the 20 predefined symptoms, more than one quarter of the PTs recognized a need for additional support in most of their older patients (Figure 3).

\section{Survey Part (II): Geriatric Palliative Concerns}

As shown in Figure 4, the five geriatric palliative concerns most frequently expressed by older patients in community pharmacies were drug-related: drug therapy options, hospital discharge, drug administration, drug-drug interactions and symptom complaints in context with medication. The three most frequently expressed nondrug-related geriatric palliative concerns were mental strain ( $45 \%$ of the respondents answered that this concern was at least often expressed by their older patients), loneliness (37\%), and mourning (31\%). The PTs saw a high need for support in drug administration, hospital discharge, drug-drug interactions, activities of daily living, and adverse drug reactions. In 17 of the 19 predefined concerns, more than one quarter of the PTs saw a need for more support in most of their older patients (Figure 5). 


\section{In how many of your older patients in the community pharmacy do you recognize a need for more support in everyday life with regard to the following symptoms?}

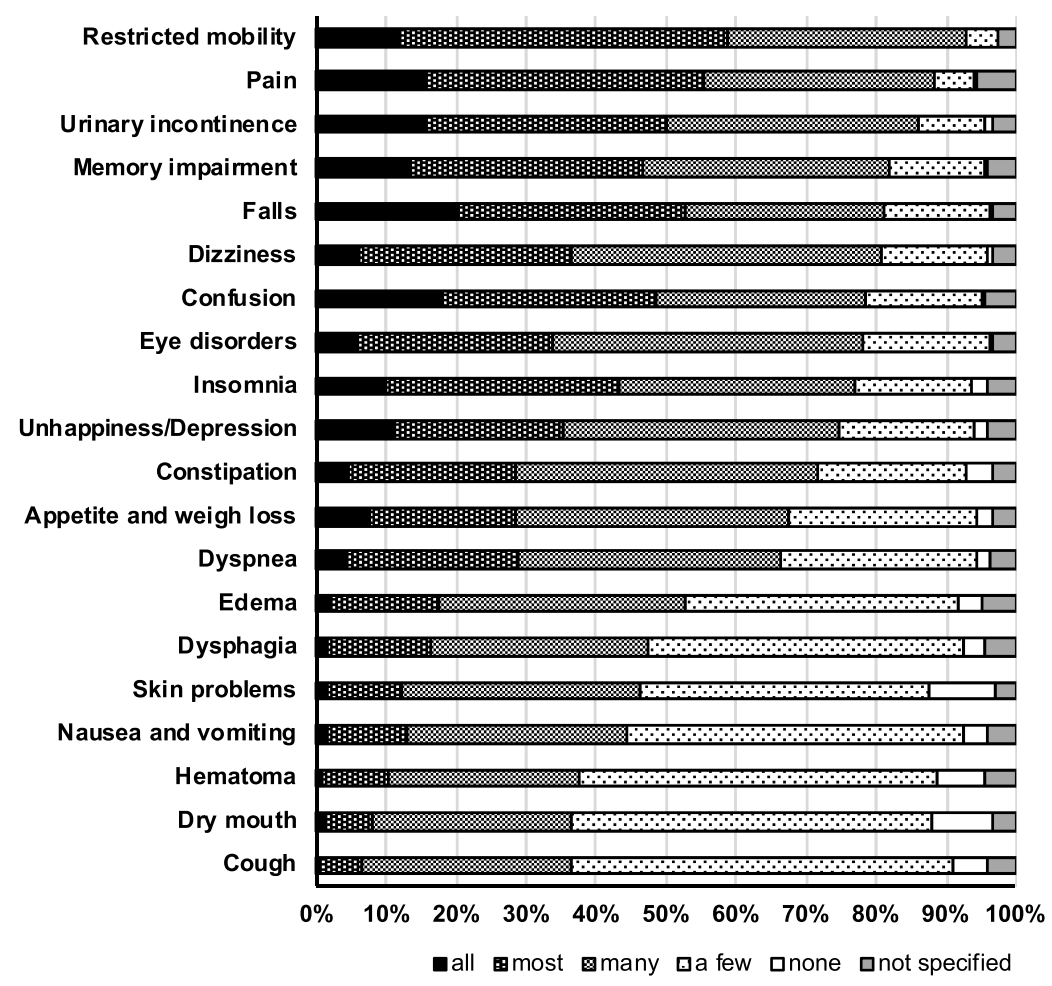

Figure 3 PTs' impression about the need for support in symptoms of older patients in pharmacy consultations. Percentages refer to the total number of $\mathrm{N}=339$ respondents.

\section{Survey Part (III): Reasons for Inadequate Care}

Two hundred and sixteen participants gave free-text answers about the reasons for inadequate care. The answers included 518 different reasons. The reasons were categorized into three main categories "Patient related aspects", "Medical care" and "General framework" and 21 subcategories (Figure 6). The most frequently mentioned reason for inadequate care was the lack of time with $70(14 \%)$ reports. Two hundred and ninety-nine of the 518 reasons $(58 \%)$ can be summarized as patient-related reasons, $140(27 \%)$ related to the medical care by health care professionals and $79(15 \%)$ to the general framework.

\section{Survey Part (IV): Desire for Multidisciplinary Cooperation and Counselling Older Patients}

PTs are most often involved in counselling on drug therapy (summative rank 1, sum of 1131 points), followed by organizational (rank 2, 1093) and logistical aspects (rank 3, 1059), and counselling on non-drug therapy (rank 4, 971). PTs spend the least time on support and assistance for older patients in their routine (rank 5, 712). According to the rated importance, the summative order is: rank 1 (1307) counselling on drug therapy, rank 2 (1133) counselling on non-drug options, rank 3 (894) support and assistance in everyday life, rank 4 (817) logistic and rank 5 (805) organizational aspects.

Eighty-seven percent (296/339) of PTs expressed the desire for more cooperation with other occupational groups. In particular, the respondents would like to see closer cooperation with general practitioners (85\%), nursing services (84\%) and palliative care physicians (39\%). In addition, $27 \%$ of PTs would like more cooperation with nutrition consultants and $28 \%$ with social workers (Table 2 ).

\section{Discussion}

Our survey with PTs adds valuable knowledge about the role of community pharmacies in the healthcare of older patients. Beyond the pharmacies' main tasks of distributing and counselling on medication, older patients seem to use pharmacies as one contact point in the health care system for their geriatric and palliative concerns. Therefore, PTs are aware of a wide range of geriatric symptoms and the need for more support in 


\section{How often are the following concerns raised by older patients in your pharmacy?}

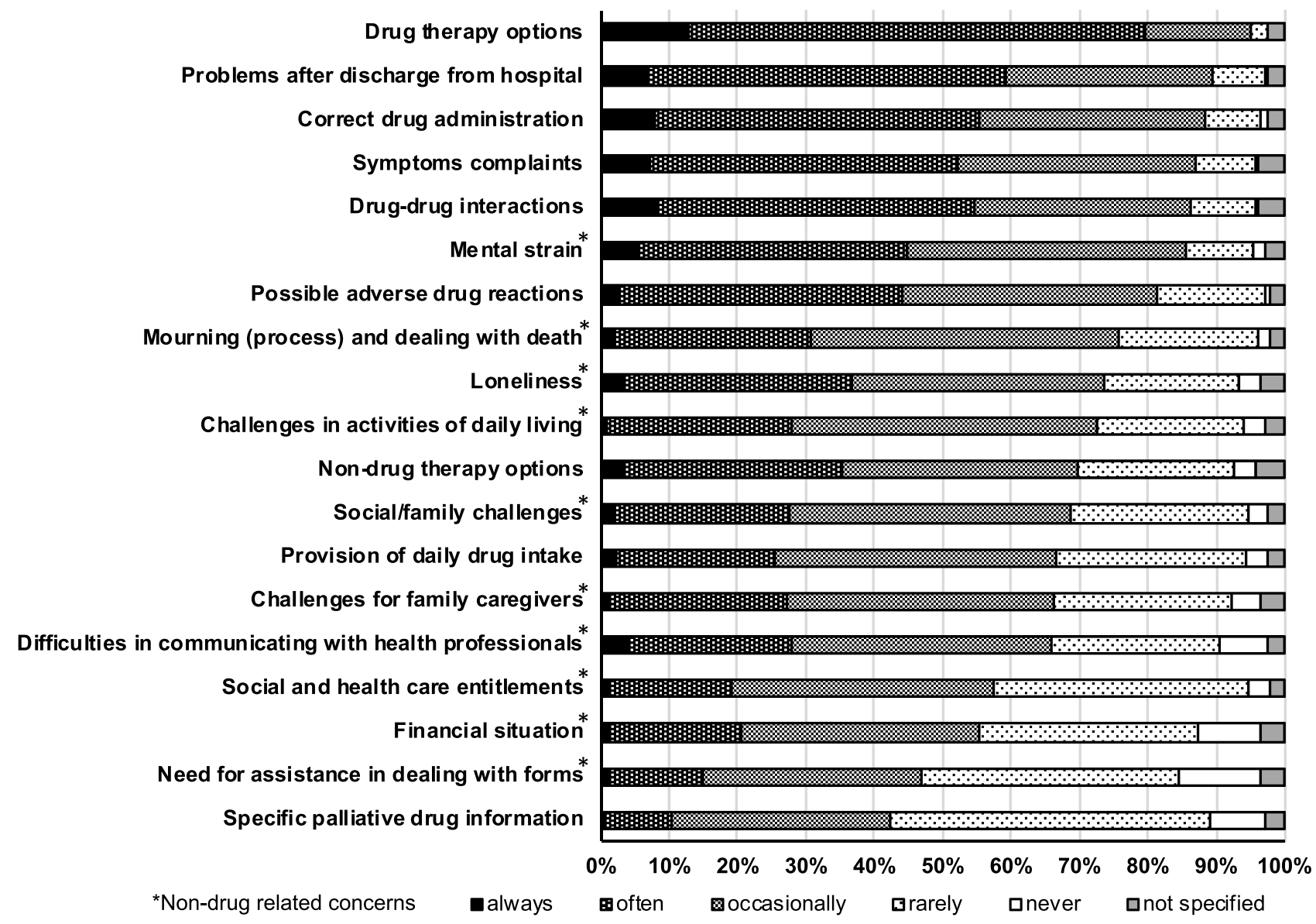

Figure 4 PTs' perception of the prevalence of geriatric palliative concerns of older patients in pharmacy consultations. Drug-related and non-drug-related geriatric palliative concerns. Percentages refer to the total number of 339 respondents. *Non-drug related concerns.

the context of their pharmaceutical consultations. As barriers to better patient care, PTs most frequently mentioned the lack of time and patient-related reasons. Specific training could make PTs even more sensitive to palliative concerns and symptomatic complaints of older patients. If a potential gap in care occurs, the pharmacist and importantly, the attending physician could be involved more quickly. PTs would like to be able to better support their older patients and to have a closer multidisciplinary collaboration with other health professionals. Hence, geriatric and palliative themes play an important role in routine pharmacy consultations, which should be incorporated more structurally in multidisciplinary care concepts.

\section{Geriatric Symptoms in Pharmacy Consultations}

PTs frequently recognize geriatric symptoms in their consultation routine and have to consider them while counselling on self-medication. For certain symptoms, eg, pain, insomnia, eye problems, dizziness and cough, our participants estimated a higher prevalence than has been detected in other studies assessing those symptoms in patients. ${ }^{23-31}$ These mentioned symptoms are common indications for self-medication, ${ }^{32,33}$ which could explain why PTs recognized them more frequently in older patients.

However, the PTs perceived some symptoms less frequently than in other studies. Especially for the symptoms of dry mouth and dysphagia, it can be concluded that patients do not address these symptoms in the pharmacy. This is relevant because those symptoms are common adverse drug reactions in older patients (eg dry mouth) or can have a negative impact on adherence (eg dysphagia). ${ }^{34-39}$ Our results, therefore, suggest that pharmacies should pay more attention to these symptoms to contribute to safe drug therapy. 


\section{In how many of your older patients in the pharmacy do you recognize a need for more support for the following concerns?}

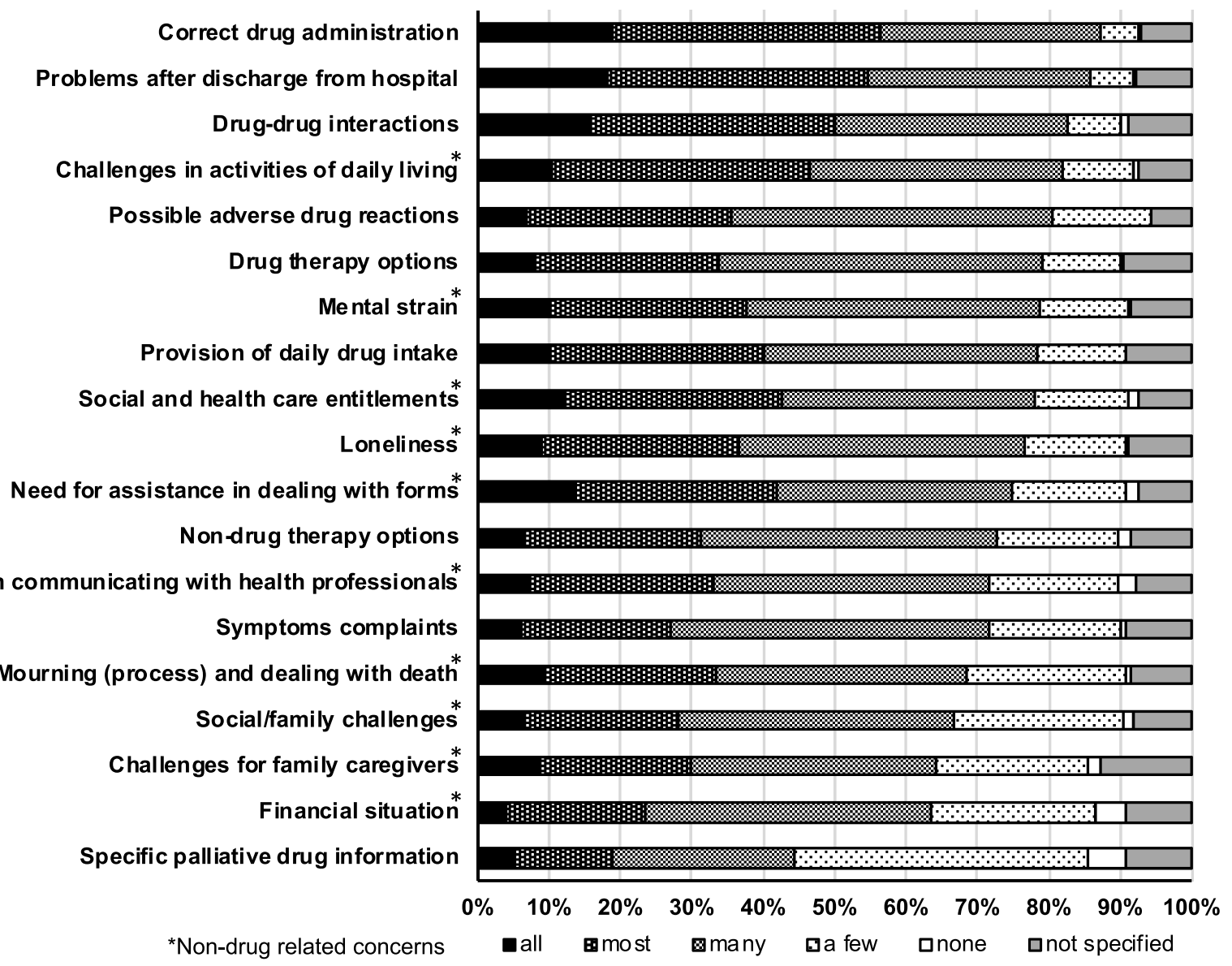

Figure 5 PTs' impression about the need for support of geriatric palliative concerns of older patients in pharmacy consultations. Drug-related and non-drug-related geriatric palliative concerns. Percentages refer to the total number of 339 respondents. *Non-drug related concerns.

For more than half of the symptoms, our respondents also recognized an increased need to support the affected patients. This underlines the undersupply of symptoms. ${ }^{40-42}$ More training in geriatric and palliative care could enable PTs to better recognize symptoms and to involve specialists if necessary.

\section{Geriatric Palliative Concerns of Older Patients in Pharmacy Consultations}

As expected in the community pharmacy setting, older patients most frequently express geriatric palliative concerns that directly relate to drug therapy. This was especially the case for drug therapy options, drug administration or drug-drug interactions. These concerns are typically part of pharmaceutical services. ${ }^{43}$ We additionally included non-drug-related concerns in our survey and asked whether older patients raise them in their pharmacy visits. Although not directly drugrelated, these concerns could also be relevant for proper drug therapy.

Older patients frequently have difficulty coping with their various physical, social and psychological challenges. Nevertheless, adequate support is missing. ${ }^{44}$ It is therefore not surprising that these patients use their local pharmacy to raise non-drug-related geriatric palliative concerns. Mourning was a frequently mentioned concern according to our PTs. Even though it is not obvious, older patients need as much support in coping with mourning as younger patients do. ${ }^{45}$ This is especially important because mourning also triggers the onset of physical and mental health problems, and can, therefore, have a negative effect on medication adherence. ${ }^{46}$ In order to better address those patients' needs in the pharmacy consultation process, all 
What reasons can you spontaneously think of why older patients do not receive sufficient support for the above-mentioned symptoms and concerns?

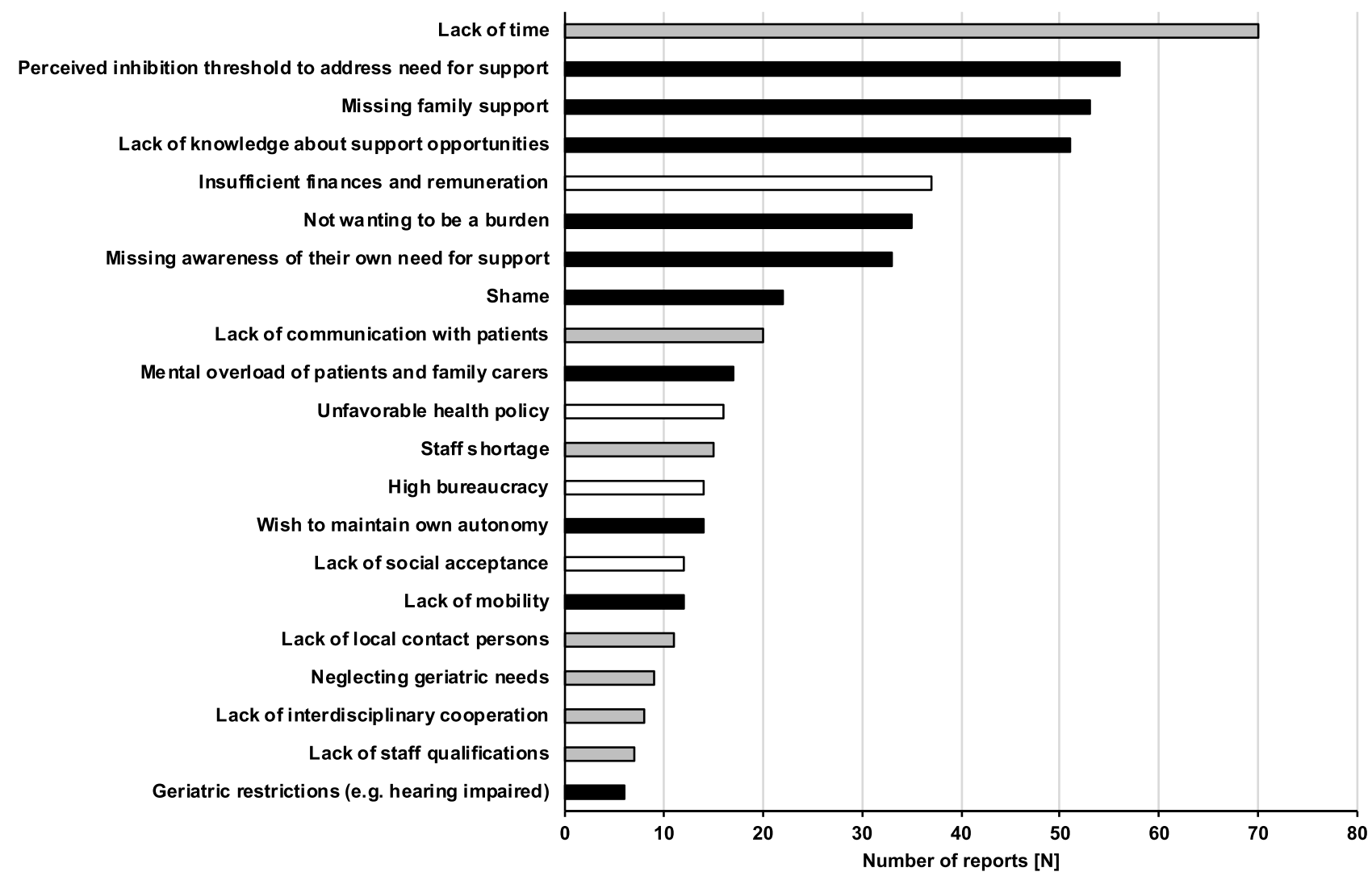

Figure 6 PTs suggested possible reasons for inadequate everyday support for older patients. Open responses to the question were categorized post-hoc: Subcategories are divided into three different main categories: patient-related aspects (black), medical care by health care professional (grey), and structure of care (white).

pharmaceutical staff should be qualified in basic palliative care concepts. ${ }^{47}$

Table 2 Pharmacist Technicians' Desire for Multidisciplinary Cooperation

\begin{tabular}{|c|c|c|}
\hline Desire for a Closer Collaboration with ${ }^{\mathbf{a}} \ldots$ & Valt & $\mathbf{N}(\%])$ \\
\hline General practitioner & 289 & $(85 \%)$ \\
\hline Nursing service & 285 & $(84 \%)$ \\
\hline Palliative physician & 132 & $(39 \%)$ \\
\hline Social worker & 95 & $(28 \%)$ \\
\hline Nutrition consultation & 92 & $(27 \%)$ \\
\hline Volunteers & 54 & $(16 \%)$ \\
\hline Pastoral care & 53 & $(16 \%)$ \\
\hline Relatives/Family $^{\mathrm{b}}$ & 7 & $(2 \%)$ \\
\hline Health insurance & 5 & $(2 \%)$ \\
\hline Senior citizens group/nursing home ${ }^{b}$ & 2 & $(<1 \%)$ \\
\hline Legal guardians ${ }^{\mathrm{b}}$ & I & $(<1 \%)$ \\
\hline Physiotherapy ${ }^{b}$ & I & $(<1 \%)$ \\
\hline Taxi/Carrier ${ }^{b}$ & I & $(<1 \%)$ \\
\hline
\end{tabular}

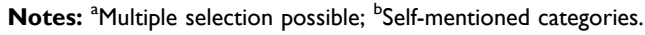

Our respondents also noted that loneliness is mentioned frequently by older patients in the community pharmacy. Loneliness is common in older patients. It represents an important risk factor for depression and anxiety disorders, which also can have a negative impact on adherence. ${ }^{4-52}$ These examples reflect the valuable information available in community pharmacies and raise the question of how to integrate it more effectively in multidisciplinary palliative and geriatric care.

\section{Better Multidisciplinary Cooperation to Overcome Inadequate Support}

According to the responding PTs, patient-related aspects were the main reasons for insufficient support in everyday life. This is in line with the literature: patients want to maintain their autonomy as long as possible and do not want to be a burden to anyone. ${ }^{53,54}$ With increasing age, more people live alone and support by family members 
decreases. This results in a lack of family support which needs to be intercepted by the healthcare system. ${ }^{55}$ Since the PTs in our study also were aware of these barriers, all health care professionals should encourage older patients to talk about their complaints and facilitate support for them.

The lack of time and personnel, as well as various problems in multidisciplinary cooperation (lack of qualifications, lack of local contact persons, neglecting geriatric needs), were also identified by the PTs as reasons for insufficient care of older patients. PTs wish to assist their older patients more with their needs and desire a closer cooperation with other healthcare professionals including palliative specialists. Therefore, based on our results, initiators of palliative care concepts would find openminded PTs and pharmacies willing to help. This could be seen as a chance to implement requested concepts that improve multidisciplinary cooperation. ${ }^{56}$ The health system should use available resources to the fullest extent possible, and the information obtained in community pharmacies, and particularly from PTs, should be better integrated into multidisciplinary health concepts.

\section{Limitations}

The survey was regionally limited to Lower Saxony, Germany. Generalization of the findings is, therefore, only possible to a limited extent. PTs in other countries may not have the same level of contact with patients. Our survey captured only the PTs' perspective, and pharmacists' perspective might differ. It further has to be considered that PTs are not trained to assess geriatric symptoms. Their perspective might, therefore, differ from the patients' perspective and their actual symptoms. Because of this, our survey is not an objective analysis of older patients' symptoms and concerns. It further does not present data about actual PT counselling. Nevertheless, our results allow a valuable insight into older patients in pharmacy consultations. Other limitations are that the descriptive analysis does not allow correlations of single items, and due to the respondent rate of $43 \%$, a selection bias cannot be excluded. Data about the PTs who did not answer the questionnaire were not available. It can further be assumed that our participants represent especially motivated PTs, since the survey was carried out within the framework of a continuing education event. We can neither exclude a social desirability bias in the respondents nor that their answers were influenced by the training. Interpreting the results of the survey is further limited because the final questionnaire was not validated. We did not calculate reliability measures such as kappa and Cronbach's alpha. Nevertheless, the questionnaire was based in part on existing validated questionnaires. For quality assurance, we pretested the questionnaire.

\section{Conclusion}

PTs see many older patients in their pharmacy who suffer from a variety of symptoms. PTs are additionally confronted in their daily counselling activities with diverse geriatric or palliative concerns of these patients. We deduce, first, a need for PT training in geriatric and palliative care. Second, multidisciplinary care concepts and research should include pharmacies because they seem to be a low-threshold contact point for older patients, who need access to adequate care.

\section{Data Sharing Statements}

Data will be available upon request from the corresponding author.

\section{Acknowledgments}

We acknowledge support from Leipzig University for Open Access Publishing. We would like to thank the Chamber of Pharmacists of Lower Saxony, in particular Petra Otto-Akrout and Julia Fabricius, the lectures Martina Dreeke-Ehrlich, Marieke Mundt, Christine Jensch, Claudia Peuke, Gesche Kober and Nicole Moritz as well as Carina and Dr. Martin Thomsen with their team of the Marien-Apotheke for organizational support. We thank Ines Wakob for proofreading the manuscript and Katherine Worthington for language editing of the manuscript and the English version of the questionnaire.

\section{Disclosure}

The authors report no conflicts of interest in this work.

\section{References}

1. Eckerblad J, Theander K, Ekdahl A, Jaarsma T, Hellstrom I. To adjust and endure: a qualitative study of symptom burden in older people with multimorbidity. Appl Nurs Res. 2015;28(4):322-327. doi:10.1016/j.apnr.2015.03.008.

2. van Lancker A, Velghe A, van Hecke A, et al. Prevalence of symptoms in older cancer patients receiving palliative care: a systematic review and meta-analysis. J Pain Symptom Manage. 2014;47(1):90-104. doi:10.1016/j.jpainsymman.2013.02.016.

3. Walke LM, Byers AL, Gallo WT, Endrass J, Fried TR. The association of symptoms with health outcomes in chronically ill adults. $J$ Pain Symptom Manage. 2007;33(1):58-66. doi:10.1016/j.jpainsymman.20 06.07.013. 
4. Khaje-Bishak Y, Payahoo L, Pourghasem B, Asghari Jafarabadi M. Assessing the quality of life in elderly people and related factors in Tabriz. Iran J Caring Sci. 2014;3(4):257-263. doi:10.5681/jcs.2014.028.

5. Ribeiro MDS, Borges MDS, Araújo TCCFD, Souza MCDS. Coping strategies used by the elderly regarding aging and death: an integrative review. Rev Bras Geriatr Gerontol. 2017;20(6):869-877. doi:10.1590/ 1981-22562017020.170083.

6. Desrichard O, Vallet F, Agrigoroaei S, Fagor D, Spini D. Frailty in aging and its influence on perceived stress exposure and stress-related symptoms: evidence from the Swiss vivre/leben/vivere study. Eur J Ageing. 2018;15(4):331-338. doi:10.1007/s10433-017-0451-2.

7. Ellis G, Sevdalis N. Understanding and improving multidisciplinary team working in geriatric medicine. Age Ageing. 2019;48 (4):498-505. doi:10.1093/ageing/afz021.

8. Fernando $\mathrm{G}$, Hughes $\mathrm{S}$. Team approaches in palliative care: a review of the literature. Int $J$ Palliat Nurs. 2019;25(9):444-452. doi:10.12968/ijpn.2019.25.9.444.

9. Voumard R, Rubli Truchard E, Benaroyo L, Borasio GD, Büla C, Jox RJ. Geriatric palliative care: a view of its concept, challenges and strategies. BMC Geriatr. 2018;18(1):220. doi:10.1186/s12877-0180914-0.

10. Oishi A, Murtagh FE. The challenges of uncertainty and interprofessional collaboration in palliative care for non-cancer patients in the community: a systematic review of views from patients, carers and health-care professionals. Palliat Med. 2014;28(9):1081-1098. doi:10.1177/0269216314531999.

11. Thoonsen B, Groot M, Engels Y, et al. Early identification of and proactive palliative care for patients in general practice, incentive and methods of a randomized controlled trial. BMC Fam Pract. 2011;3 (12):123. doi:10.1186/1471-2296-12-123.

12. O’Connor M, Pugh J, Jiwa M, Hughes J, Fisher C. The palliative care interdisciplinary team: where is the community pharmacist? J Palliat Med. 2011;14(1):7-11. doi:10.1089/jpm.2010.0369.

13. Eickhoff C, Hämmerlein A, Griese N, Schulz M. Nature and frequency of drug-related problems in self-medication (over-the-counter drugs) in daily community pharmacy practice in Germany. Pharmacoepidemiol Drug Saf. 2011;21(3):254-260. doi:10.1002/ pds.2241.

14. Mc Namara KP, Dunbar JA, Philpot B, et al. Potential of pharmacists to help reduce the burden of poorly managed cardiovascular risk. Aust J Rural Health. 2012;20(2):67-73. doi:10.1111/j.14401584.2012.01259.x.

15. Abrahamsen B, Burghle AH, Rossing C. Pharmaceutical care services available in Danish community pharmacies. Int J Clin Pharm. 2020;42(2):315-320. doi:10.1007/s11096-020-00985-7.

16. Gray SL, Hart LA, Perera S, et al. Meta-analysis of interventions to reduce adverse drug reactions in older adults. $J$ Am Geriatr Soc. 2018;66(2):282-288. doi:10.1111/jgs.15195.

17. Portenoy RK, Thaler HT, Kornblith AB, et al. The memorial symptom assessment scale: an instrument for the evaluation of symptom prevalence, characteristics and distress. Eur J Cancer. 1994;30A (9):1326-1336. doi:10.1016/0959-8049(94)90182-1

18. National Cancer Institute. Common terminology criteria for adverse events (CTCAE). version 5.0; 2017. Available from: https://ctep. cancer.gov/protocoldevelopment/electronic_applications/docs/ctcae v5 quick reference 8.5x11.pdf. Accessed November 10, 2020.

19. Somers A, Petrovic M, Robays H, Bogaert M. Reporting adverse drug reactions on a geriatric ward: a pilot project. Eur J Clin Pharmacol. 2003;58(10):707-714. doi:10.1007/s00228-002-0535-5.

20. Gamondi C, Larkinand P, Payne S. Core competencies in palliative care: an EAPC white paper on palliative care education -part 1. Eur J Palliat Care. 2013;20(2):86-91.

21. International Pharmaceutical Federation. The FIP community pharmacy section - vision 2020; 2019. Available from: https://www.fip. org/community-pharmacy. Accessed November 10, 2020.
22. Pelicano-Romano J, Neves MR, Amado A, Cavaco AM. Do community pharmacists actively engage elderly patients in the dialogue? Results from pharmaceutical care consultations. Health Expect. 2015;18(5):1721-1734. doi:10.1111/hex.12165

23. Gibson SJ, Lussier D. Prevalence and relevance of pain in older persons. Pain Med. 2012;13(2):23-26. doi:10.1111/j.1526-4637.2012.01349.x.

24. Larsson C, Hansson EE, Sundquist K, Jakobsson U. Chronic pain in older adults: prevalence, incidence, and risk factors. Scand J Rheumatol. 2017;46(4):317-325. doi:10.1080/03009742.2016.1218543.

25. Patel KV, Guralnik JM, Dansie EJ, Turk DC. Prevalence and impact of pain among older adults in the United States: findings from the 2011 national health and aging trends study. Pain. 2013;154 (12):2649-2657. doi:10.1016/j.pain.2013.07.029.

26. Patel D, Steinberg J, Patel P. Insomnia in the elderly: a review. J Clin Sleep Med. 2018;14(6):1017-1024. doi:10.5664/jcsm.7172.

27. Hashemi H, Khabazkhoob M, Nabovati P, et al. The prevalence of age-related eye disease in an elderly population. Ophthalmic Epidemiol. 2017;24(4):222-228. doi:10.1080/09286586.2016.1270335.

28. Khalaj M, Barikani A, Ghasemi H. Eye disorders in old people. Glob $J$ Health Sci. 2012;5(1):79-86. doi:10.5539/gjhs.v5n1p79.

29. de Moraes SA, de Souza Soares WJ, Ferriolli E, Rodrigues Perracini M. Prevalence and correlates of dizziness in community-dwelling older people: a cross sectional population based study. BMC Geriatr. 2013;13(4). doi:10.1186/1471-2318-13-4.

30. Dros J, Maarsingh OR, Beem L, et al. Impact of dizziness on everyday life in older primary care patients: a cross-sectional study. Health Qual Life Outcomes. 2011;9(44):44. doi:10.1186/ 1477-7525-9-44.

31. Song WJ, Morice AH, Kim MH, et al. Cough in the elderly population: relationships with multiple comorbidity. PLoS One. 2013;8(10): e78081. doi:10.1371/journal.pone.0078081.

32. Shafie M, Eyasu M, Muzeyin K, Worku Y, Martín-Aragón S Prevalence and determinants of self-medication practice among selected households in Addis Ababa community. PLoS One. 2018;13(3):e0194122. doi:10.1371/journal.pone.0194122.

33. Statista [homepage on the internet] Berlin: over the counter drugs and self-medication; 2019. Available from: https://de.statista.com/statis tik/studie/id/23076/dokument/otc-arzneimittel-und-selbstmedikationstatista-dossier/. Accessed November 10, 2020.

34. Soini H, Routasalo P, Lauri S, Ainamo A. Oral and nutritional status in frail elderly. Spec Care Dentist. 2008;23(6):209-215. doi:10.1111/ j.1754-4505.2003.tb00314.x.

35. Han P, Suarez-Durall P, Mulligan R. Dry mouth: a critical topic for older adult patients. J Prosthodont Res. 2015;59(1):6-19. doi:10.1016/j. jpor.2014.11.001

36. Allepaerts S, Delcourt S, Pertermans J. Swallowing disorders in elderly patients: a multidisciplinary approach. Rev Med Liege. 2014;69(5-6):349-356.

37. Turley R, Cohen S. Impact of voice and swallowing problems in the elderly. JAMA Otolaryngol Head Neck Surg. 2009;140(1):33-36. doi:10.1016/j.otohns.2008.10.010.

38. Tan ECK, Lexomboon D, Sandborgh-Englund G, Haasum Y, Johnell K. Medications that cause dry mouth as an adverse effect in older people: a systematic review and metaanalysis. J Am Geriatr Soc. 2018;66(1):76-84. doi:10.1111/jgs.15151.

39. Marquis J, Schneider MP, Payot V. Swallowing difficulties with oral drugs among polypharmacy patients attending community pharmacies. Int J Clin Pharm. 2013;35(6):1130-1136. doi:10.1007/s11096-0139836-2.

40. Kaye AD, Baluch A, Scott JT. Pain management in the elderly population: a review. Ochsner J. 2010;10(3):179-187.

41. Barry LC, Abou JJ, Simen AA, Gill TM. Under-treatment of depression in older persons. J Affect Disord. 2012;136(3):789-796. doi:10.1016/j.jad.2011.09.038.

42. Borsheski R, Johnson QL. Pain management in the geriatric population. Mo Med. 2014;111(6):508-511. 
43. Avalere Health LLC. Exploring pharmacists' role in a changing healthcare environment; 2014. Available from: https://www.nacds. org/pdfs/comm/2014/pharmacist-role.pdf. Accessed November 10, 2020.

44. Abdi S, Spann A, Borilovic J, de Witte L, Hawley M. Understanding the care and support needs of older people: a scoping review and categorisation using the WHO international classification of functioning, disability and health framework (ICF). BMC Geriatr. 2019;19 (1):195. doi:10.1186/s12877-019-1189-9.

45. Lekalakala-Mokgele E. Death and dying: elderly persons' experiences of grief over the loss of family members. S Afr Fam Pract. 2018;60(5):151-154. doi:10.1080/20786190.2018.1475882.

46. Yap AF, Thirumoorthy T, Kwan YH. Systematic review of the barriers affecting medication adherence in older adults. Geriatr Gerontol Int. 2016;16(10):1093-1101. doi:10.1111/ggi.12616.

47. Radbruch L, Payne S, Bercovitch M, et al. White Paper on standards and norms for hospice and palliative care in Europe: part 2. Eur $J$ Palliat Care. 2010;17(1):22-32.

48. Ong AD, Uchino BN, Wethington E. Loneliness and health in older adults: a mini-review and synthesis. Gerontology. 2016;62 (4):443-449. doi:10.1159/000441651.

49. Beutel ME, Klein EM, Brähler E, et al. Loneliness in the general population: prevalence, determinants and relations to mental health. BMC Psychiatry. 2017;17(1):97. doi:10.1186/s12888-017-1262-x.
50. Golden J, Conroy RM, Bruce I, et al. Loneliness, social support networks, mood and wellbeing in community-dwelling elderly. Int J Geriatr Psychiatry. 2009;24(7):694-700. doi:10.1002/gps.2181.

51. Grenard JL, Munjas BA, Adams JL, et al. Depression and medication adherence in the treatment of chronic diseases in the United States: a meta-analysis. J Gen Intern Med. 2011;26(10):1175-1182. doi:10.1007/s11606-011-1704-y.

52. Santana L, Fontenelle LF. A review of studies concerning treatment adherence of patients with anxiety disorders. Patient Prefer Adherence. 2011;5:427-439. doi:10.2147/PPA.S23439.

53. Canvin K, MacLeod CA, Windle G, Sacker A. Seeking assistance in later life: how do older people evaluate their need for assistance? Age Ageing. 2018;47(3):466-473. doi:10.1093/ageing/afx189.

54. Cahill EBA, Lewis LM, Barg FK, Bogner HR. You don't want to burden them older adults' views on family involvement in care. J Fam Nurs. 2009;15(3):295-317. doi:10.1177/1074840709337247.

55. Reher D, Requena M. Living alone in later life: a global perspective. Popul Dev Rev. 2018;44(3):427-454. doi:10.1111/padr.12149.

56. Nancarrow SA, Booth A, Ariss S, et al. Ten principles of good interdisciplinary team work. Hum Resour Health. 2013;11(1):19. doi:10.1186/1478-4491-11-19.
Journal of Multidisciplinary Healthcare

\section{Publish your work in this journal}

The Journal of Multidisciplinary Healthcare is an international, peerreviewed open-access journal that aims to represent and publish research in healthcare areas delivered by practitioners of different disciplines. This includes studies and reviews conducted by multidisciplinary teams as well as research which evaluates the results or conduct of such teams or healthcare processes in general. The journal

\section{Dovepress}

covers a very wide range of areas and welcomes submissions from practitioners at all levels, from all over the world. The manuscript management system is completely online and includes a very quick and fair peer-review system. Visit http://www.dovepress.com/testimonials. php to read real quotes from published authors. 